\title{
Synthetic Animated Realities
}

\author{
Simon Finn \\ Artist \\ Melbourne \\ Australia \\ http://www.simonfinn.info \\ Simonfinn.info@gmail.com
}

\section{INTRODUCTION}

Computation can effectively represent highly complex processes, from which series of sequential static images can be derived directly. This is due to the unique sovereignties over spatial and temporal representation that it affords.

This opportunity for complex spatiotemporal simulation offered by digital technologies allows a subversion of the computer's traditional role as an image production device, through its use in my own work to create preliminary sketches as a basis for sequential pieces finished in traditional analogue forms. I am currently exploring these connections via the presentation of a variety of spatial and temporal sequential imagery in a series of exhibitions, and supporting contextual research.

\section{WORKFLOW}

The workflow for this investigation begins with 3D modelling of found artefacts (Figure 1) in Autodesk Maya, from which a new structure is developed. Once a complex digital model is completed, it is run through a physics simulation to degrade its original structure. A sample of various stages in this process is also 3D printed using a fused deposition modelling process (Figure 2). The range of static imagery generated by this process is then staged and reinterpreted through the hand using traditional drawing processes (Figure 3). This final set of drawn work then forms the basis for curated exhibitions (Figures 1-3).

\section{GROUNDS AND PRACTICE MODELS}

The grounds for this direction derive from recent work on theories of apparent motion (Anderson \& Anderson 1993). This work has proven vital in dispelling inaccurate accounts of the mechanics of the recognition of motion in film through obsolete notions of persistence of vision.
In my case, this modern approach to moving image construction has offered a strong framework for considering the validity of artistic experimentation with a motion-based subject matter that disperses into the static. As the perception of motion in sequential images is constructed cognitively rather than through retinal persistence, my work asks the viewer to explore this process through foregrounding the constructed and the staged.

The direction of my research is further supported by an investigation of a variety of historical approaches to image construction, where each of these supportive prior examples has been conditioned by an artistic focus on a work's ability to operate as sequential art. Through this aspect of the research, I have begun to map both an historical territory and simultaneously a sampling of wordless narratives that draws linkages between sequential art and my current studio practice.

The range of works sampled is intended to inform a contemporary approach that is based in spatial and temporal sequentiality, and includes work from practitioners as diverse as Hogarth, Duchamp, Marey and Guo-Qiang.

\section{FURTHER DIRECTIONS}

Exploring these connections has raised questions surrounding the instability of digital depictions in an age of increased image saturation, whether new ways of interpreting meaning through art practice become evident when the construction process is slowed down through the act of making, and what the consequences for drawing will be when simulation technology is considered the initial sketch?

\section{REFERENCES}

Anderson, J. and Anderson, B. (1993) The Myth of Persistence of Vision Revisited. Journal of Film and Video, 45(1):3-12 (Spring). 


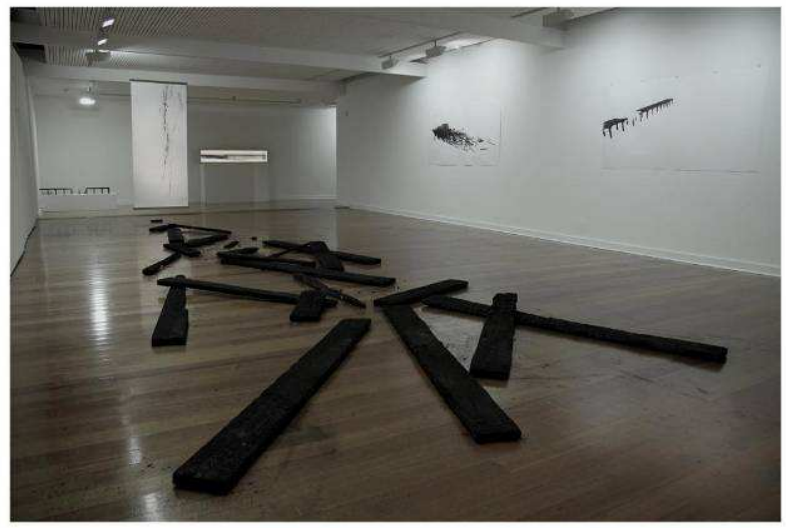

Figure 1: Installation view, burnt pier planks. George Patton Gallery, 2012.

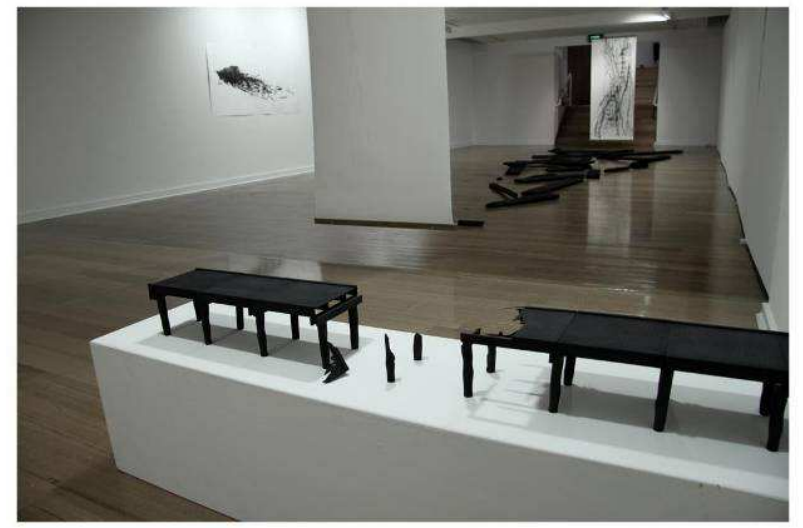

Figure 2: Installation view, 3D pier model. George Patton Gallery, 2012.

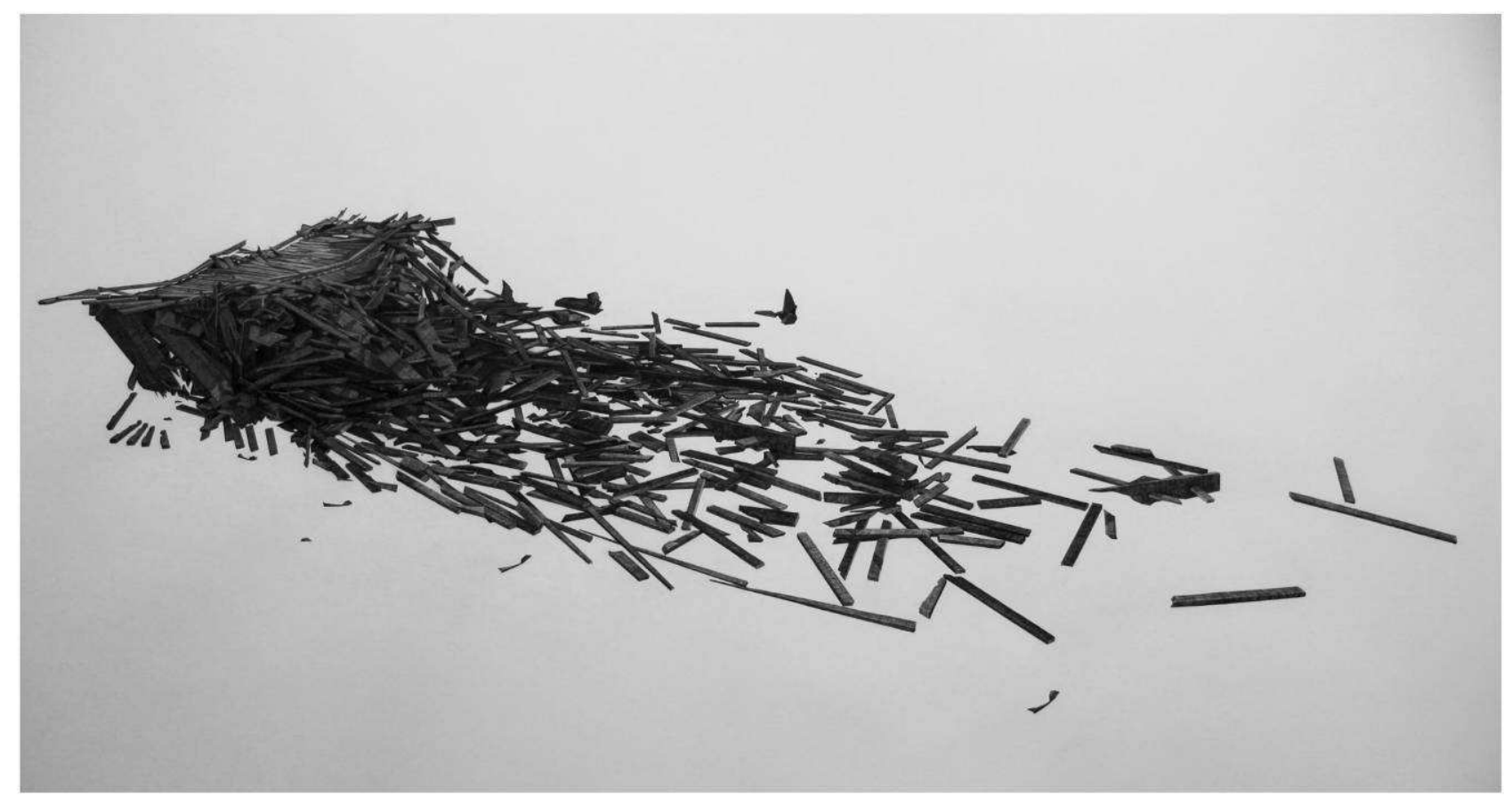

Figure 3: Pier Collapse. Charcoal on paper, $200 \times 100 \mathrm{~cm}$. George Patton Gallery, 2012. 